\title{
Isolation and characteristics of multi-drug resistant Streptococcus porcinus from the vaginal secretions of sow with endometritis
}

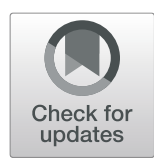

Yawen Wang ${ }^{1 \dagger}$, Haiyong Guo ${ }^{2 \dagger}$, Yun Bai ${ }^{1}$, Tanqing $\mathrm{Li}^{1}$, Ruitao Xu', Tairan Sun ${ }^{3}$, Jicheng $\mathrm{Lu}^{3}$ and Qinye Song ${ }^{1 *}$ (D)

\begin{abstract}
Background: Sow endometritis is a common disease in pig breeding farms after artificial insemination, which leads to gray-green vaginal secretions and decreased conception rates. It is important to perform an etiologic diagnosis for effective treatments and control of diseases. The aim of this study was to carry out a pathogenic detection in five specimens of vaginal secretions collected from sick pigs with endometritis, implement identification of the pathogens by phenotypic detection and $16 \mathrm{~s}$ rDNA sequence and phylogeny analysis, and determinate antibiotic susceptibility of the isolates.

Results: A Streptococcus strain was isolated and identified from all of the five specimens. The isolate was positive for Voges-Proskauer (V-P) and for the hydrolysis of arginine, esculin and myelin-associated glycoprotein (MAG). Acid formation was observed for sorbitol, mushroom sugar, sucrose, and glucose. The 165 rDNA sequence of the isolate possessed $99.93 \%$ similarity to that of Streptococcus porcinus. The phylogenetic analysis of $16 \mathrm{~S}$ rDNA sequence showed that the isolate belonged to the same clade as the $S$. porcinus strains from humans, pigs, and other animals. The isolate exhibited multi-drug resistance to aminoglycosides, quinolones, macrolides and tetracyclines except being sensitive to some $\beta$ - lactams such as penicillin G, cephalothin, cefazolin, cephradine and cefuroxime.

Conclusions: A S. porcinus isolate with multi-drug resistance was identified from vaginal secretions of sows with endometritis in one pig breeding farm, which suggests that the sow endometritis was caused by S. porcinus infection during artificial insemination. This study indicates that sensitive antibiotics such as penicillin $\mathrm{G}$ or some cephalosporins could be used for treatment of the diseases. In addition, the study hints that bacterial multi-drug resistance is a tough problem for disease treatment in pig farms.
\end{abstract}

Keywords: Sow, Endometritis, Streptococcus porcinus, Multi-drug resistance

\section{Background}

Porcine endometritis is a common genital disease in sows, which is induced by the infection by bacteria, viruses, parasites, fungal toxins, and other pathogenic factors [1-3]. The pigs with endometritis often exhibit a

\footnotetext{
* Correspondence: songqinye@126.com

†Yawen Wang and Haiyong Guo contributed equally to this work. ${ }^{1}$ Hebei Province Research Center of Veterinary Biological Engineering and Technology, College of Veterinary Medicine, Hebei Agricultural University, Baoding 071000, China

Full list of author information is available at the end of the article
}

decreased appetite, fever, extrados, brown mucous or purulent discharge from the vagina, anestrus or irregular estrus, infertility or miscarriage breeding. Moreover, the porcine endometritis can cause severe sepsis and even death $[4,5]$. E. coli, Streptococcus, Staphylococcus, Corynebacterium, Pseudomonas aeruginosa, and Proteus are major pathogens that cause endometritis $[1,6]$. In some large-scale farms of China, $47.6 \%$ of the sows are culled for various anomalies among which 41.4 and $17.7 \%$ are eliminated due to endometritis and other reproductionrelated diseases, respectively, $18.5 \%$ result from limb 
hoof disease, and the remaining part is attributed to other pathologic conditions [4].

The species Streptococcus porcinus belonging to the genus Streptococcus is commonly associated with pyogenic infections, abortion and endocarditis of pigs, as well as genitourinary tract infection of women [7-9]. $S$. porcinus was first identified in pigs in 1984, and then isolated from bovine milk $[7,8]$. The organism has also been detected in the urogenital tracts of pregnant women [9-11]. S. porcinus is usually detected in pig tonsils. $19.5 \%$ of tonsils of the pigs in slaughterhouses were positive for the isolation of $S$. porcinus, which is just less than the prevalence of $S$. suis infections (53.7\%) [12]. Swine $S$. porcinus causes pig lymph node abscess, throat abscess, pneumonia, arthritis, and endocarditis, as well as sow abortion $[1,8,13,14]$, but there are rare reports on sow endometritis caused by S. porcinus.

In this study, to confirm the cause of a sow endometritis case from a pig breeding farm in Hebei Province, China, five vaginal secretion samples from the sick sows were detected in etiology by isolation and culture, phenotypic examinations and $16 \mathrm{~S}$ rRNA sequence analysis of pathogen. In addition, antibiotic susceptibility assays of the isolate were carried out in order to instruct an effective treatment of the disease.

\section{Results}

\section{Cultural and morphological characteristics of the isolate}

Bacteria with similar cultural and morphological characteristics were isolated in all vaginal secretion samples from five sick pigs. The bacterial isolates showed a poor growth on ordinary nutrient agar with fewer small tipsized colonies, but a good growth on blood agar and serum agar plates with off-white, smooth-surfaced, and regular-edged microcolonies. And transparent $\beta$-type hemolysis was present around the colonies on the blood agar plate. The isolates did not grow on the eosin methylene blue and MacConkey agar plates. The bacteria precipitated at the bottom of the tube containing serum broth after overnight incubation. The microscopy analysis revealed that the isolates appeared grampositive cocci in a single, pairs, or short-chain arrangement (Fig. 1). No similar cultural and morphological bacteria were detected from the vaginal secretion samples of all healthy pigs.

\section{Physiological characteristics of the isolate}

To differentiate whether the isolated bacteria was Streptococcus or Staphylococcus, we performed a catalase test. The bubbles observed for positive controls after dropping 3\% hydrogen peroxide solution onto the staphylococcal reference strain. In contrast, no bubbles generated for the isolated bacteria and the negative control after adding 3\% hydrogen peroxide

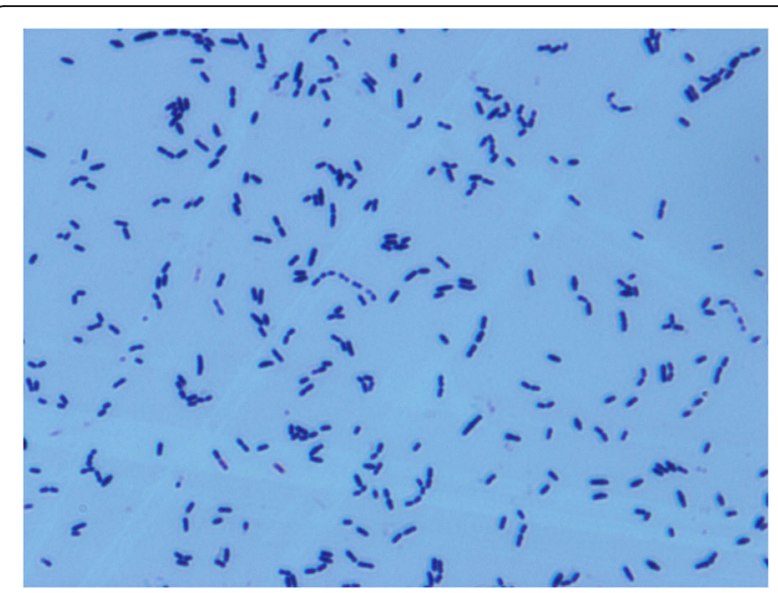

Fig. 1 Morphological characteristics of the isolate in solid medium under the microscope $(\times 1000)$

onto the isolated bacteria and the streptococcal reference strain, which indicated that the isolated strains were catalase-negative. Further biochemical assays revealed that the isolates were positive for VogesProskauer (V-P) and for the hydrolysis of arginine, esculin and myelin-associated glycoprotein (MAG). Negative results were observed for the production of dipeptidyl aminopeptidase (DPP), polymethylgalacturonase (PMG) and for hydrolysis of temozolomide (TMZ). Acid formation exhibited for sorbitol, mushroom sugar, sucrose, and glucose, but did not for lactose, raffinose, xylose, and adonitol (Table 1).

Table 1 Phenotypic characteristics of the isolated bacteria

\begin{tabular}{lll}
\hline Phenotypic characteristic & Reaction & S. porcinus \\
\hline Catalase & $-^{\mathrm{b}}$ & - \\
Voges-Proskauer (V-P) & $+^{\mathrm{c}}$ & + \\
Arginine & + & + \\
Esculin & + & + \\
Polymethylgalacturonase (PMG) & - & - \\
Temozolomide (TMZ) & - & - \\
Dipeptidyl aminopeptidas (DPP) & - & - \\
Myelin-associated glycoprotein (MAG) & + & + \\
Sorbitol & + & + \\
Adonitol & - & $/$ \\
Mushroom sugar & + & + \\
Lactose & - & - \\
Xylose & - & $/$ \\
Sucrose & + & - \\
Glucose & + & - \\
Raffinose & - & + \\
\hline
\end{tabular}

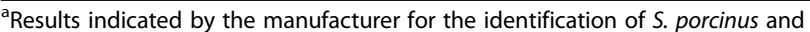
the references (Martin et al., [9]; Duarte et al., [10])

${ }^{b}$ Negative reaction; ${ }^{c}$ Positive reaction; ${ }^{d}$ no data 
Phylogenetic analysis of 16S rRNA gene sequence of the isolate

In order to genetically classify the isolated streptococci, we amplified the $16 \mathrm{~S}$ rDNA sequence. PCR products of expected size were obtained after PCR using bacterial $16 \mathrm{~S}$ rRNA gene sequence-specific primers. DNA sequencing analysis showed that the size of the amplified nucleic acid sequence was 1428 bp (GenBank accession number: MN148888).

Pairwise alignment of the isolated strain with reference streptococcal strains revealed that the $16 \mathrm{~S}$ rRNA gene sequence of the isolated strain had about 99.93, 98.18, 96.60, 96.64, 96.78 and $96.33 \%$ similarities to those of $S$. porcinus, S. pseudoporcinus, S. uberis, S. parauberis, $S$. canis and S. dysgalactiae, respectively, from human or animal.

The phylogenetic tree based on $16 \mathrm{~S}$ rDNA sequences suggested that the isolated strain was in the same small branch with the human or animal S. porcinus strains in GenBank, which indicated a closer genetic relationship between the isolated strain and $S$. porcinus strains compared to other subspecies. The isolate was in different small branches with $S$. pseudoporcinus, but co-located in a large branch, indicating a closer genetic relationship with S. pseudoporcinus. However, it situated in distinct branches with S. uberis, S. canis, S. dysgalactiae, and $S$. parauberis strains, which displayed a distant genetic relationship (Fig. 2).

\section{Multi-drug resistance of the isolate}

In order to clarify further biological characteristics of the isolate, we conducted antibiotics susceptibility assays. The results were shown in Table 2. Among tested 25 different antibiotics, the isolate was only sensitive to penicillin G, cephalothin, cefazolin, cephradine, and cefuroxime, but it was resistant to most antibiotics such as lincomycin, nitrofurantoin, rifampicin, aminoglycosides, quinolones, macrolides, and tetracyclines. The results demonstrated that the isolate is multi-drug resistant.

\section{Discussion}

Endometritis is one of the major diseases causing a high sow elimination rate and $6.6 \%$ of breeding sows death in large-scale farms [15]. Many pathogens, including virus such as Japanese encephalitis, porcine reproductive and respiratory syndrome virus, and pseudorabies virus, bacteria such as E. coli, Streptococcus, Staphylococcus,

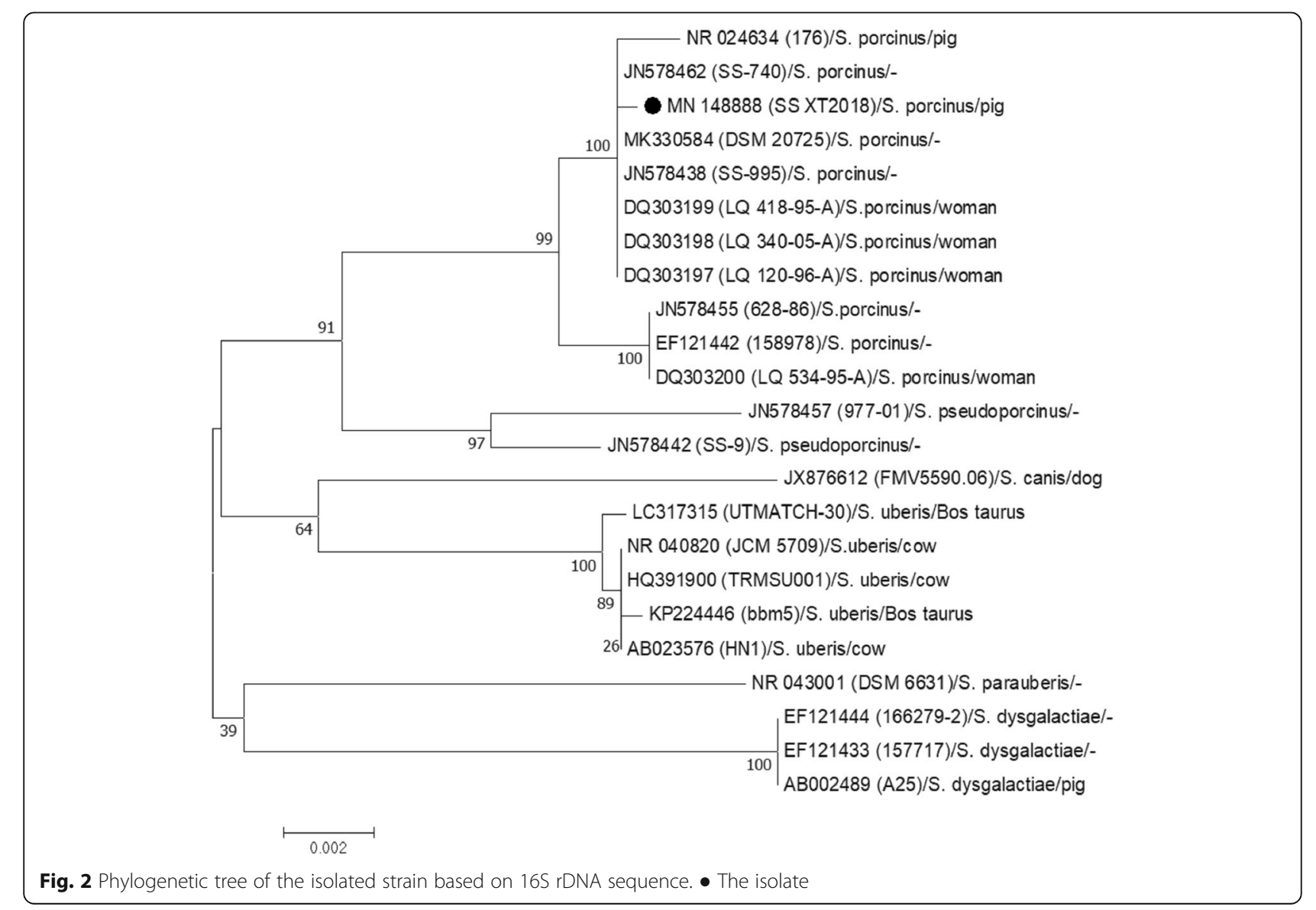


Table 2 Drug susceptibility of the isolated bacteria

\begin{tabular}{|c|c|c|c|c|c|c|}
\hline \multirow[t]{2}{*}{ Antibiotics } & \multirow{2}{*}{$\begin{array}{l}\text { Drug } \\
\text { contents } \\
\text { ( } \mu \mathrm{g} / \\
\text { piece) }\end{array}$} & \multicolumn{3}{|c|}{ Criteria for inhibition zone $(\mathrm{mm})$} & \multirow{2}{*}{$\begin{array}{l}\text { Measured } \\
\text { inhibition } \\
\text { zone (mm) }\end{array}$} & \multirow[t]{2}{*}{ Results } \\
\hline & & Resistance (R) ${ }^{a}$ & Intermediate $(\mid)^{b}$ & $\begin{array}{l}\text { Sensitivity } \\
(S)^{c}\end{array}$ & & \\
\hline \multicolumn{7}{|l|}{$\beta$ - lactams } \\
\hline Ampicillin & 10 & $\leq 18$ & $19-25$ & $\geq 26$ & $19.87 \pm 0.23$ & I \\
\hline Penicillin G & $10 I U$ & $\leq 19$ & $20-27$ & $\geq 28$ & $28.10 \pm 0.17$ & $S$ \\
\hline Amoxicillin & 20 & $\leq 13$ & $14-17$ & $\geq 18$ & 0 & $\mathrm{R}$ \\
\hline Cephalothin & 30 & $\leq 14$ & $15-17$ & $\geq 18$ & $25.03 \pm 0.06$ & $S$ \\
\hline Cefazolin & 30 & $\leq 14$ & $15-17$ & $\geq 18$ & $24.00 \pm 0.10$ & $S$ \\
\hline Cephradine & 30 & $\leq 14$ & $15-17$ & $\geq 18$ & $29.10 \pm 0.17$ & $S$ \\
\hline Cefuroxime & 30 & $\leq 14$ & $15-22$ & $\geq 23$ & 27.00 & $S$ \\
\hline Cefotaxime & 30 & $\leq 25$ & $26-27$ & $\geq 28$ & 0 & $\mathrm{R}$ \\
\hline Ceftriaxone & 30 & $\leq 25$ & $26-27$ & $\geq 28$ & $26.07 \pm 0.12$ & 1 \\
\hline \multicolumn{7}{|l|}{ Aminoglycosides } \\
\hline Amikacin & 30 & $\leq 14$ & $15-16$ & $\geq 17$ & 0 & $\mathrm{R}$ \\
\hline Streptomycin & 10 & $\leq 11$ & $12-14$ & $\geq 15$ & 0 & $\mathrm{R}$ \\
\hline Kanamycin & 30 & $\leq 13$ & $14-17$ & $\geq 18$ & 0 & $\mathrm{R}$ \\
\hline \multicolumn{7}{|l|}{ Macrolides } \\
\hline Erythromycin & 15 & $\leq 13$ & $14-22$ & $\geq 23$ & 0 & $\mathrm{R}$ \\
\hline Roxithromycin & 15 & $\leq 13$ & $14-22$ & $\geq 23$ & 0 & $\mathrm{R}$ \\
\hline Acetylspramycin & 30 & $\leq 13$ & $14-22$ & $\geq 23$ & 0 & $\mathrm{R}$ \\
\hline \multicolumn{7}{|l|}{ Tetracyclines } \\
\hline Tetracycline & 30 & $\leq 18$ & $19-22$ & $\geq 23$ & $2.93 \pm 0.06$ & $\mathrm{R}$ \\
\hline Minocycline & 30 & $\leq 14$ & $15-18$ & $\geq 19$ & $8.90 \pm 0.17$ & $\mathrm{R}$ \\
\hline Doxycycline & 30 & $\leq 12$ & $13-15$ & $\geq 16$ & 2.00 & $\mathrm{R}$ \\
\hline \multicolumn{7}{|l|}{ Quinolones } \\
\hline Ofloxacin & 5 & $\leq 12$ & $13-15$ & $\geq 16$ & 0 & $\mathrm{R}$ \\
\hline Ciprofloxacin & 5 & $\leq 15$ & $16-20$ & $\geq 21$ & 0 & $\mathrm{R}$ \\
\hline Norfloxacin & 10 & $\leq 12$ & $13-16$ & $\geq 17$ & 0 & $\mathrm{R}$ \\
\hline Enrofloxacin & 10 & $\leq 12$ & $13-16$ & $\geq 17$ & 0 & $\mathrm{R}$ \\
\hline Lincomycin & 2 & $\leq 14$ & $15-20$ & $\geq 21$ & $10.97 \pm 0.06$ & $\mathrm{R}$ \\
\hline Macrodantin & 300 & $\leq 14$ & $15-16$ & $\geq 17$ & 0 & $\mathrm{R}$ \\
\hline Rifampicin & 5 & $\leq 16$ & $17-18$ & $\geq 19$ & $17.67 \pm 0.58$ & I \\
\hline
\end{tabular}

${ }^{\mathrm{a}}$ Resistance; ${ }^{\mathrm{b}}$ Intermediate; ${ }^{\mathrm{c}}$ Sensitivity

clostridia, Pseudomonas aeruginosa, and parasites (e.g. trichomonas), can cause pig endometritis [1-6]. If disinfection is not strict, the breeding process, including artificial insemination, birth, midwifery, and abortion, can lead to infections and result in endometritis $[1,16,17]$.

To improve the breeding and reproduction rate, artificial insemination is widely used in intensive pig farms. However, semen is easily contaminated with microbial pathogens carried by boar or contaminated during semen fluids collection and storage process $[16,17]$. In the current study, the clinical endometritis cases were likely correlated with contamination of semen and artificial insemination because symptoms of endometritis emerged just 3 to 5 days after insemination. Therefore, we carried out an etiological examination to determine its causes.

In order to ensure the accuracy of detection results, we combined phenotypic and molecular biological approaches to determine the causative agent of sow endometritis, and set up vaginal secretion samples of clinical healthy sows and gilts in the same farm as the case controls. In addition to bacteriological testing, PCR was employed for detecting classical swine fever virus (CSFV), porcine reproductive and respiratory syndrome virus (PRRSV), porcine circovirus type 2 (PCV2) and porcine circovirus type 3 (PCV3) in the sow vaginal 
secretions and did not find these viral nucleic acids (supplementary data). These results suggest that the sow endometritis was caused by a bacterial infection most likely due to contamination of semen and artificial insemination.

Indeed, we isolated and identified a Gram-positive Streptococcus from the vaginal secretions of the sick sows based on Gram-staining, microscopy, catalase and biochemical assays. The isolated Streptococcus with $\beta$ hemolysis in short chains arrangement under the microscope is negative to catalase, and positive to V-P test and to acid formation of sorbitol, mushroom sugar, sucrose and glucose, and hydrolysis of arginine and esculin. The most of these characteristics are consistent with those of Streptococcus porcinus in spite of exhibition of some variable reaction in the study $[9,10]$.

$16 \mathrm{~S}$ rRNA gene sequences contain highly and moderately conserved sequence regions, and highly variable sequence region, which is a powerful molecular target and widely used in classification and identification of bacteria from clinical isolates [18-20]. 16S rRNA gene sequencing is a very useful method for differentiating S. porcinus from S. pseudoporcinus isolates, and for determining the taxonomic status of isolates from animal, human and dairy sources $[21,22]$. In order to further clarify the subspecies of the Streptococcus isolate in this study, we amplified the16S rRNA DNA sequence and conducted a comparative phylogenetic analysis. The results suggest that the Streptococcus isolate from vaginal secretions is likely to be Streptococcus porcinus because its $16 \mathrm{~S}$ rRNA sequence is highly similar to those of the Streptococcus porcinus reference strains from both humans and pigs.

Bacterial resistance is an important global concern of public health especially in the last 20 years. The rapid increase in drug-resistant strains has caused a serious problem in clinical treatments of human and animal infectious diseases [23-25]. Resistant isolates of animal origin are very common and easily disseminated between animal and humans from contaminated food [24]. Wang et al. [25] reported that multidrug-resistant Salmonella Typhimurium isolates dramatically increased among the salmonella isolated from human, animal and retail milk between 2011 to 2016. Resistances of S. porcinus for erythromycin, minocycline, sulfamethoxazoletrimethoprim, streptomycin and tetracycline were described in previous study [26]. In this study, we observed that the S. porcinus strain had multi-drug resistance to antibiotics including aminoglycosides, quinolones, macrolides, and tetracyclines except being sensitive to some $\beta$ - lactams such as penicillin G, cephalothin, cefazolin, cephradine and cefuroxime. These data suggest that sensitive antibiotics such as penicillin G or some cephalosporins could be used for treating this disease through local delivery into the uterus following washing and sterilizing vulva with disinfectant fluid. Meanwhile, it is necessary to implement more strict clinical veterinary medicine practice, including disinfection procedure during semen collection and artificial insemination.

Though an experimental proof would be of high interest for demonstrating the occurrence of endometritis during artificial insemination by detection of semen and instruments for insemination or animal experiment, we did not do these tests in this study because the semen and other relevant insemination materials had not been gotten then, and animal experiment was limited in fields. Nevertheless, we estimated that the occurrence of endometritis could be associated with artificial insemination since sows unfertilized artificially were not attacked by this disease in this farm. In addition, it happened just on days 3-5 after artificial insemination.

In summary, the identification of S. porcinus provides important information for determining the cause of sow endometritis. The evaluation of antibiotic susceptibility of the isolate could contribute to the treatment of sow endometritis from bacterial infection. It should be noted that bacterial multi-drug resistance is a great challenge to the current disease control.

\section{Conclusions}

This study demonstrates that the sow endometritis was caused by $S$. porcinus infection during artificial insemination in the pig breeding farm. The isolate has multidrug resistance to most antibiotics applied clinically, which may be a great challenge for the control of animal infectious diseases. In addition, sensitive antibiotics such as penicillin $\mathrm{G}$ or some cephalosporins could be used for treating sow endometritis by $S$. porcinus infection in pig farm.

\section{Methods \\ Case presentation}

Eighteen multiparous sows and twenty-four replacement gilts had a fever and lost appetite 3 to 5 days after artificial insemination and generated large amounts of pale yellow vaginal secretions. On the second estrus, endometritis occurred, and gilts estrus conception rate was significantly decreased or breeding capacity was totally abolished. Five random sick pigs' vaginal secretions (3 from sows and 2 from gilts) were collected aseptically using $10 \mathrm{~mL}$ disposable syringes with needles removed and put into $15 \mathrm{~mL}$ sterile collection tubes for laboratory testing on day four after presentation of the clinical signs. Five of vaginal secretion samples were subsequently collected from three healthy sows and two healthy gilts, which were not fertilized by artificial insemination as the case controls. After the samples had been collected, the pigs were released but the diseased 
Table $\mathbf{3}$ Information of reference streptococcus strains

\begin{tabular}{|c|c|c|c|}
\hline Strains & GenBank accession number & Host & Organism \\
\hline DSM 20725 & MK330584 & - & S. porcinus \\
\hline SS-740 & JN578462 & - & S. porcinus \\
\hline SS-995 & JN578438 & - & S. porcinus \\
\hline LQ 120-96-A & DQ303197 & woman & S. porcinus \\
\hline LQ 340-05-A & DQ303198 & woman & S.porcinus \\
\hline 176 & NR_024634 & pig & S. porcinus \\
\hline LQ 418-95-A & DQ303199 & woman & S.porcinus \\
\hline $628-86$ & JN578455 & - & S.porcinus \\
\hline 158,978 & EF121442 & - & S. porcinus \\
\hline LQ 534-95-A & DQ303200 & woman & S. porcinus \\
\hline SS-9 & JN578442 & - & S. pseudoporcinus \\
\hline $977-01$ & JN578457 & - & S. pseudoporcinus \\
\hline JCM 5709 & NR_040820 & cow & Suberis \\
\hline HN1 & AB023576 & cow & S. uberis \\
\hline TRMSU001 & HQ391900 & cow & S. uberis \\
\hline UTMATCH-30 & LC317315 & Bos taurus & S. uberis \\
\hline bbm5 & KP224446 & Bos taurus & S. uberis \\
\hline 157,717 & EF121433 & - & S. dysgalactiae \\
\hline A25 & AB002489 & pig & S. dysgalactiae \\
\hline $166,279-2$ & EF121444 & - & S. dysgalactiae \\
\hline DSM 6631 & NR_043001 & - & S. parauberis \\
\hline FMV5590.06 & JX876612 & dog & S. canis \\
\hline
\end{tabular}

Note: -, no data

ones were separated from the healthy and got clinical treatment.

\section{Characteristics of bacterial culture}

All of the vaginal secretion samples were taken and streaked onto ordinary nutrient agar (Beijing Biotech AOB Star Co., China) and serum-agar plates with 5\% sheep serum (Gibco) in ordinary nutrient agar medium. After incubation $18 \sim 24 \mathrm{~h}$ at $37^{\circ} \mathrm{C}$, colony morphology was examined, Gram stained, and the morphology of bacteria staining was observed under a microscope.

The single colony was re-streaked onto the ordinary nutrient agar, sheep serum agar, sheep blood agar, MacConkey agar, and eosin methylene blue agar plates (Beijing Biotech AOB Star Co., China), respectively, and incubated overnight at $37^{\circ} \mathrm{C}$. Phenotypic characteristics of colonies were further observed. Single colony was picked, inoculated into serum nutrient broth containing $5 \%$ sheep serum in the ordinary nutrient broth, and incubated for $16-18 \mathrm{~h}$ at $37^{\circ} \mathrm{C}$ with shaking at $200 \mathrm{rpm}$. The bacterial cultures were taken for Gram staining and observed under the microscope.

\section{Catalase test}

To conduct catalase examination, the isolated bacterial colonies were picked and placed on clean glass slides, and the strain ATCC25923 of Staphylococcus and the strain ATCC 27335 of Streptococcus was as the positive or the negative control, respectively; $3 \%$ hydrogen peroxide (Sigma) was dropped onto the bacteria on the slides. The appearance of large bubbles indicated that the catalase was positive, whereas no bubbles indicated that it was negative.

\section{Biochemical examinations}

To perform biochemical assays, the bacterial cells from cultures were inoculated into biochemical identification microtubes (Hangzhou Binhe Microorganism Regent Co., Ltd., China), respectively, and cultured for $24 \mathrm{~h}$ at $37^{\circ} \mathrm{C}$ according to the manufacturer's instructions.

\section{PCR of 16S rRNA gene sequences}

The bacterial 16S rRNA gene (rDNA) sequence universal primers 16SF (5'-AGAGTTTGATCCTGGCTCAG$\left.3^{\prime}\right)$ and 16SR (5'-GGTTACCTTGTTACGACTT-3') were utilized for amplification of $16 \mathrm{~S}$ rRNA sequence from the isolated bacterial cells. PCR reaction system 
was set as follows: $25 \mu \mathrm{L}$ of $2 \times$ Taq Plus MasterMix (Beijing ComWin Biotech Co., Ltd. China), $1 \mu \mathrm{L}$ upstream and downstream primers, respectively, $2 \mu \mathrm{L}$ of bacterial suspension cells, and $21 \mu \mathrm{L} \mathrm{ddH}_{2} \mathrm{O}$. The reaction program was: pre-denaturation at $94^{\circ} \mathrm{C}$ for $3 \mathrm{~min}$, followed by 35 cycles of denaturation at $94{ }^{\circ} \mathrm{C}$ for $45 \mathrm{~s}$, annealing at $52^{\circ} \mathrm{C}$ for $1 \mathrm{~min}$, extension at $72{ }^{\circ} \mathrm{C}$ for 1 min, and a final extension at $72{ }^{\circ} \mathrm{C}$ for $10 \mathrm{~min}$. PCR products were detected on $1 \%$ agarose gel electrophoresis, purified, and then ligated into the $\mathrm{pM} 18-\mathrm{T}$ vector (TaKaRa Dalian, China). The PCR products were sequenced at Sangon Biotech (Shanghai) Co., Ltd., China.

\section{$16 \mathrm{~S}$ rRNA gene sequence analysis}

The 16S rDNA sequence from the isolate, designated as SS XT2018 (GenBank ID: MN148888), was compared with the reference sequences in GenBank (Table 3) using CLUSTAL W program of molecular evolutionary genetics analysis software (MEGA), version 7.0. An unrooted phylogenetic tree was constructed using the Neighbor-joining method with the maximum likelihood method and bootstrap tests of 1000 replicates.

\section{Antibiotics susceptibility test}

$\mathrm{K}-\mathrm{B}$ disk diffusion method was used for testing the susceptibility of the isolate to antibiotics. Single colony was inoculated into serum Mueller-Hinton (MH) broth (BD/ Difco) with $5 \%$ sheep serum until a turbidity of culture reached 0.5 McFarland units (equivalent to $1.5 \times 10^{8} \mathrm{col}-$ ony forming unit $/ \mathrm{mL}$ ) at $37^{\circ} \mathrm{C}$. The bacterial broth was spread onto the surface of serum $\mathrm{MH}$ agar plates and antibiotics such as $\beta$-lactams, aminoglycosides, macrolides, tetracyclines, quinolones, lincomycin, macrodantin and rifampicin (Hangzhou Binho Microbial Agent Co., China) (Table 3) were pasted onto the plates. The inhibition zone diameters on the agar plates were measured 18 to $24 \mathrm{~h}$ after incubation at $37^{\circ} \mathrm{C}$. The isolate's susceptibility to these antibiotics was determined according to the manufacturers' designated standard. The experiment was carried out three times, and the final inhibition zone diameters were expressed as the mean of repeats.

\section{Supplementary information}

Supplementary information accompanies this paper at https://doi.org/10. 1186/s12917-020-02365-9.

Additional file 1. Primers used for RT-PCR detection in this study.

Additional file 2. Viral DNA/RNA extraction and PCR.

\section{Abbreviations}

V-P: Voges-Proskauer; MAG: Myelin-associated glycoprotein; DPP: Dipeptidyl aminopeptidase; PMG: Polymethylgalacturonase; TMZ: Temozolomide; PCR: Polymerase chain reaction; CSFV: Classical swine fever virus;
PRRSV: Porcine reproductive and respiratory syndrome virus; PCV2: Porcine circovirus type 2; PCV3: Porcine circovirus type 3

\section{Acknowledgements}

We gratefully thank Dr. Yinduo Ji for his excellent technical assistance.

\section{Authors' contributions}

YW and $\mathrm{HG}$ equally contributed to this work by performing the experiments and drafting the manuscript. YB and TL performed identification of the bacteria. RX and TS collected samples, and assisted in data analysis. JL performed the experiments. QS conceived the study, analyzed data, edited and finalized the manuscript. All authors have read and approved the final version of the manuscript.

\section{Funding}

This work was supported by the National Key Research and Development Program of China (2016YFD0500703-4), the Hebei Province Science and Technology Support Program (17226613D-2), and the Master Candidate Innovation Capacity Training Funding Project of Hebei Education

Department (CXZZSS2018056). The funders had no role in study design, data collection and analysis, decision to publish, or preparation of the manuscript.

\section{Availability of data and materials}

The datasets generated and/or analysed during the current study are available in the GenBank repository, https://www.ncbi.n/m.nih.gov/nuccore/ MN148888.

\section{Ethics approval and consent to participate}

This study was ethically approved by the Hebei Agricultural University's Animal Welfare and Ethical Review Board. All procedures were performed in accordance with the guidelines for the care and use of animals of Hebei Agricultural University (China) and with current Chinese legislation, following the written and informed consent of the pig farm owners.

Consent for publication

Not applicable.

\section{Competing interests}

The authors declare that they have no competing interests.

\section{Author details}

${ }^{1}$ Hebei Province Research Center of Veterinary Biological Engineering and Technology, College of Veterinary Medicine, Hebei Agricultural University, Baoding 071000, China. ${ }^{2}$ School of Life Science, Jilin Normal University, Siping 136000, China. ${ }^{3}$ Baoding Animal Disease Control and Prevention Center, Baoding 071000, Hebei, China.

Received: 23 November 2019 Accepted: 10 May 2020

Published online: 20 May 2020

\section{References}

1. Gottschalk M. Streptococci. In: Zimmerman J, Karriker L, Ramirez A, Schwartz K, Stevenson G, editors. Diseases of swine. 10th ed. West Sussex: WileyBlackwell Publishing; 2012. p. 334-5.

2. Wang J, Li C, Nesengani LT, Gong Y, Zhang S, Lu W. Characterization of vaginal microbiota of endometritis and healthy sows using high-throughput pyrosequencing of 16S rRNA gene. Microb Pathog. 2017;111:325-30.

3. Lager KM, Halbur PG. Gross and microscopic lesions in porcine fetuses infected with porcine reproductive and respiratory syndrome virus. J Vet Diagn Investig. 1996:8:275-82.

4. Luo Z, Yuan AW. Etiological analysis and control measures on sow endometritis in intensive pig farms. Hunan Anim Husbandry Vet. 2009;3: $25-7$

5. Shen YS, Ji QY, Zhang L, Zhao CB. Treatment effect of drug Endometritis-l on sow endometritis. Anim Husbandry Vet. 2012:44:82-3.

6. Jana B, Kucharski J, Dzienis A, Deptuła K. Changes in prostaglandin production and ovarian function in gilts during endometritis induced by Escherichia coli infection. Anim Reprod Sci. 2007:97:137-50.

7. Collins MD, Farrow JAE, Katie V, Kandler O. Taxonomic studies on streptococci of serological groups $E, P, U$, and $V$ : a description of Streptococcus porcinus sp. nov. Syst Appl Microbiol. 1984;5:402-13. 
8. Wessman GE. Biology of the group E streptococci: a review. Vet Microbiol. 1986;12:297-328.

9. Martin C, Fermeaux V, Eyraud JL, Aubard Y. Streptococcus porcinus as a cause of spontaneous preterm human stillbirth. J Clin Microbiol. 2004;42:4396-8.

10. Duarte RS, Barros RR, Facklam RR, Teixeira LM. Phenotypic and genotypic characteristics of Streptococcus porcinus isolated from human sources. J Clin Microbiol. 2005:43:4592-601.

11. Pereira N, Powell AM, Nyirjesy P, Plante LA. Vaginorectal Streptococcus porcinus in pregnancy: an emerging pathogen? J Low Genit Tract Dis. 2013; 17:e18-21.

12. O'Sullivan T, Friendship R, Blackwell T, Pearl D, McEwen B, Carman S, Slavić D, Dewey C. Microbiological identification and analysis of swine tonsils collected from carcasses at slaughter. Can J Vet Res. 2011;5:106-11.

13. Pérez-Sancho M, Vela Al, García-Seco T, González S, Domínguez L, Fernández-Garayzábal JF. Usefulness of MALDI-TOF MS as a diagnostic tool for the identification of streptococcus species recovered from clinical specimens of pigs. PLoS One. 2017;12:e0170784.

14. Plagemann O. Streptococcus porcinus as a cause of abortion in swine. Zentbl Vet Med B. 1988;35:770-2.

15. Chagnon M, D'Allaire S, Drolet R. A prospective study of sow mortality in breeding herds. Can J Vet Res. 1991;55:180-4.

16. Maes D, Nauwynck H, Rijsselaere T, Mateusen B, Vyt P, de Kruif A, Van Soom A. Diseases in swine transmitted by artificial insemination: an overview. Theriogenology. 2008;70:1337-45.

17. Maes D, Van Soom A, Appeltant R, Arsenakis I, Nauwynck H. Porcine semen as a vector for transmission of viral pathogens. Theriogenology. 2016;85:27-38.

18. Gabas T, Podglajen I, Cheminet G, Gagnard JC, Wyplosz B. Diagnostic accuracy of $16 \mathrm{~S}$ rDNA PCR in bacterial pyomyositis: a prospective study. J Inf Secur. 2019;79:462-70.

19. Mishra A, Nam GH, Gim JA, Lee HE, Jo A, Kim HS. Current challenges of streptococcus infection and effective molecular, cellular, and environmental control methods in aquaculture. Mol Cells. 2018;41:495-505.

20. Saito N, Hida A, Koide Y, Ooka T, Ichikawa Y, Shimizu J, Mukasa A, Nakatomi H, Hatakeyama S, Hayashi T, Tsuji S. Culture-negative brain abscess with Streptococcus intermedius infection with diagnosis established by direct nucleotide sequence analysis of the 16s ribosomal RNA gene. Intern Med. 2012;51:211-6.

21. Shewmaker PL, Steigerwalt AG, Whitney AM, Morey RE, Graziano JC, Facklam RR, Musser KA, Merquior VL, Teixeira LM. Evaluation of methods for identification and determination of the taxonomic status of strains belonging to the Streptococcus porcinus-Streptococcus pseudoporcinus complex isolated from animal, human, and dairy sources. J Clin Microbiol. 2012:50:3591-7.

22. Gaudreau C, Simoneau E, Labrecque $\mathrm{O}$, Laurence RA, Laferrière C, Miller M, Raynal L, Rallu F. Epidemiological, biochemical and antimicrobial susceptibility characteristics of Streptococcus pseudoporcinus isolated in Quebec, Canada, from 1997 to 2006. J Med Microbiol. 2007;56(Pt 12):1620-4.

23. Gargiullo L, Del Chierico F, D'Argenio P, Putignani L. Gut microbiota modulation for multidrug-resistant organism decolonization: present and future perspectives. Front Microbiol. 2019;10:1704.

24. Zając M, Sztromwasser P, Bortolaia V, Leekitcharoenphon P, Cavaco LM, Ziętek-Barszcz A, Hendriksen RS, Wasyl D. Occurrence and characterization of mcr-1-positive Escherichia coli isolated from food-producing animals in Poland, 2011-2016. Front Microbiol. 2019;10:1753. https://doi.org/10.3389/ fmicb.2019.01753.

25. Wang X, Biswas S, Paudyal N, Pan H, Li X, Fang W, Yue M. Antibiotic resistance in Salmonella Typhimurium isolates recovered from the food chain through National Antimicrobial Resistance Monitoring System between 1996 and 2016. Front Microbiol. 2019;10:985. https://doi.org/10. 3389/fmicb.2019.00985.

26. Lämmler C, Cirak N, Smola J. Studies on biochemical, serological and further characteristics of Streptococcus porcinus. Zentralbl Veterinarmed B. 1998:45:235-43.

\section{Publisher's Note}

Springer Nature remains neutral with regard to jurisdictional claims in published maps and institutional affiliations.

Ready to submit your research? Choose BMC and benefit from:

- fast, convenient online submission

- thorough peer review by experienced researchers in your field

- rapid publication on acceptance

- support for research data, including large and complex data types

- gold Open Access which fosters wider collaboration and increased citations

- maximum visibility for your research: over $100 \mathrm{M}$ website views per year

At BMC, research is always in progress.

Learn more biomedcentral.com/submissions 